\title{
Perancangan Eksperimen untuk Meningkatkan Kualitas Ketangguhan Material dengan Pendekatan Analisis General Factorial Design (Studi Kasus: Produk Solid Surface)
}

\author{
Lithrone Laricha Salomon ${ }^{1 *}$, Wilson Kosasih ${ }^{2}$, Sauw Oscar Angkasa ${ }^{3}$ \\ $1 *, 2)$ Staf Pengajar Program Studi Teknik Industri Universitas Tarumanagara, \\ 3) Alumni Program Studi Teknik Industri Universitas Tarumanagara, \\ email : laricha_salomon@yahoo.com ${ }^{1}$, wilsonk@ft.untar.ac.id ${ }^{2}$, soscar_angkasa@yahoo.com ${ }^{3}$
}

\begin{abstract}
PT WLS is a company that produce solid surface product. The variance of shape and design that can be produced is very high and can be customized to the demand. The problem that occur in this company is that sometimes the product fractured during delivery and production. To cope this problem, an experiment design with General Factorial Design is used to determine the best material composition that can increase the toughness of the material. Two factors are determined to be the main factors that determine the toughness of the materials which is the amount of hardener and the type of material used. Charpy test was used to determine the toughness of the samples with a $55 \mathrm{~mm} \times 10 \mathrm{~mm} \times 10 \mathrm{~mm}$ dimension. Based on the analysis done, the amount of catalyst, the type of material used, and the interaction between those two factors have a significant effect to the materials toughness value and to get the optimal result for a $100 \mathrm{~mm} \times 100 \mathrm{~mm} \times 9$ $\mathrm{mm}$ sample, it was advised to use $3 \mathrm{ml}$ of hardener and $\mathrm{Al}(\mathrm{OH}) 3$ with HWF specifications.
\end{abstract}

Keywords: general factorial design, toughness, optimal

\begin{abstract}
Abstrak
PT WLS merupakan perusahaan yang membuat produk solid surface. Variansi bentuk dan warna yang dapat diproduksi sangatlah tinggi dan dapat disesuaikan dengan permintaan konsumen. Permasalahan yang dihadapi oleh perusahaan adalah banyak terjadinya produk yang pecah baik pada saat pengiriman material maupun saat produksi. Untuk mengatasi permasalahan ini, maka dilakukanlah perancangan eksperimen dengan metode General Factorial Design untuk menentukan komposisi bahan dasar terbaik yang dapat meningkatkan ketangguhan material. Terdapat dua faktor yang diyakini mempengaruhi nilai ketangguhan material yaitu banyaknya katalis dan jenis bahan campuran yang digunakan. Pengujian ketangguhan material dilakukan dengan Charpy test dengan sampel berukuran $55 \mathrm{~mm} \times 10 \mathrm{~mm} \times 10 \mathrm{~mm}$. Berdasarkan analisis yang dilakukan, diperoleh hasil bahwa faktor banyaknya katalis, jenis bahan campuran, dan interaksi kedua faktor tersebut mempunyai pengaruh yang signifikan terhadap hasil ketangguhan material dan agar didapatkan hasil yang optimal maka untuk membuat sampel berukuran $100 \mathrm{~mm} \times 100 \mathrm{~mm} \times 9 \mathrm{~mm}$, disarankan menggunakan bahan katalis sebanyak $3 \mathrm{ml}$ dan bahan campuran $\mathrm{Al}(\mathrm{OH})_{3}$ spesifikasi HWF 50.
\end{abstract}

Kata Kunci: Human Error, Human Reliability Assessment, Hierarchical Task Analysis, Human Error Assessment and Reduction Technique

\section{Pendahuluan}

*Korespondensi Penulis

PT. WLS merupakan perusahaan yang memproduksi solid surface yang biasa digunakan un- 
tuk pengganti marmer pada meja resepsionis ataupun meja dapur. Solid surface merupakan produk yang terbuat dari bahan dasar resin. Solid surface sering dipakai sebagai pengganti marmer karena produk dapat dibuat dengan warna, corak warna, maupun bentuk yang beraneka ragam. Bidang usaha PT. WLS ini tergolong bidang usaha yang sedang berkembang cepat mengingat banyaknya perumahan dan apartemen yang terus dibangun sekarang ini. Kesempatan usaha dan kompetisi yang terus berkembang menuntut perusahaan untuk terus meningkatkan kinerjanya agar dapat terus bersaing dengan kompetitor dan memenuhi permintaan konsumen. Timbulnya produk cacat merupakan hal yang pasti terjadi dalam sebuah perusahaan manufaktur.

Walaupun demikian, timbulnya produk cacat tersebut harus dikontrol sehingga jumlahnya seminimal mungkin. Permasalahan yang terjadi adalah sering ditemuinya cacat produk pecah/retak baik ketika saat dipindahkan ataupun sedang dalam proses pengiriman. Hal ini tentunya sangat merugikan karena walaupun masih dapat diperbaiki namun akan sangat mengganggu kelancaran produksi dan distribusi.

Tujuan dari penelitian ini adalah:

1. Mengetahui komposisi pencetakan produk yang dapat meningkatkan ketangguhan material

2. Mengetahui pengaruh dari katalis dan bahan campuran terhadap ketangguhan material

3. Mengetahui pengaruh faktor interaksi terhadap ketangguhan material

\section{Tinjauan Pustaka}

\subsection{Desain Faktorial}

Banyak eksperimen yang dilakukan dengan melibatkan dua atau lebih faktor. Dengan desain faktorial, maka setiap kemungkinan level kombinasi dari semua faktor akan diselidiki. Sebagai contoh, apabila terdapat a level dari faktor A dan b level dari faktor B, maka replikasi percobaan akan dilakukan untuk setiap kombinasi ab. Faktor yang dikombinasikan pada desain faktorial ini seringkali disebut crossed. Efek dari suatu faktor didefinisikan sebagai respons yang dihasilkan dari perubahan level faktor tersebut. Hal ini seringkali disebut sebagai efek utama karena mengacu pada faktor primer dari percobaan. Selain efek utama, terdapat pula efek interaksi yaitu perbedaan antara efek satu faktor pada level yang berbeda dari faktor lain.

Penggunaan desain faktorial dalam perancangan suatu eksperimen tentunya memiliki beberapa kelebihan maupun kekurangan. Berikut ini adalah beberapa hal yang menjadi dasar pertimbangan:

\section{Kelebihan}

(a) Lebih efisien dalam menggunakan sumber-sumber yang ada

(b) Informasi yang diperoleh lebih komprehensif karena kita bisa mempelajari pengaruh utama dari interaksi

(c) Hasil percobaan dapat diterapkan dalam suatu kondisi yang lebih luas karena kita mempelajari kombinasi dari berbagai factor

\section{Kekurangan}

(a) Analisis statistika menjadi lebih kompleks

(b) Terdapat kesulitan dalam menyediakan satuan percobaan yang relatif homogen

(c) Pengaruh dari kombinasi perlakuan tertentu mungkin tidak berarti apaapa sehingga terjadi pemborosoan sumber daya yang ada

Rancangan percobaan dengan desain faktorial ini pada umumnya mempunyai tiga tujuan utama yaitu:

1. Mengukur pengaruh variabel terhadap hasil

2. Menentukan variabel yang paling berpengaruh terhadap hasil

3. Mengukur interaksi antar-variabel terhadap hasil

Selain pengaruh faktor utama, pengaruh interaksi antar faktor terhadap hasil percobaan merupakan suatu hal yang penting untuk ditinjau. Hal ini disebabkan oleh pengaruh suatu faktor terhadap hasil terkadang juga sangat dipengaruhi oleh jumlah atau ada tidaknya faktor lain.

Cara lain untuk menggambarkan konsep interaksi adalah dengan permukaan respons dan plot kontur. Terdapat beberapa model matematis yang dapat digunakan untuk menggambarkan permukaan respons dan plot kontur tersebut yaitu:

1. Model efek

$$
Y_{i j k}=\mu+\tau_{i}+\beta_{j}+\tau \beta_{i j}+\varepsilon_{i j k}\left\{\begin{aligned}
i & =1,2, . ., a \\
j & =1,2, . ., b \\
k & =1,2, . ., n
\end{aligned}\right.
$$


dimana:

$\mu=$ efek rata-rata keseluruhan;

$\tau_{i}=$ efek faktor A level ke-i;

$\beta_{j}=$ efek faktor B level ke-j;

$\tau \beta_{i j}=$ efek interaksi faktor A dan B;

$\varepsilon_{i j k}=$ error.

2. Model efek rata-rata

$$
Y_{i j k}=\mu_{i j}+\varepsilon_{i j k}\left\{\begin{aligned}
i & =1,2, . ., a \\
j & =1,2, . ., b \\
k & =1,2, . ., n
\end{aligned}\right.
$$

dengan rata-rata dari sel ke-ij adalah:

$$
\mu_{i j}=\mu+\tau_{i}+\beta_{j}+\tau \beta_{i j}
$$

dimana:

$\mu=$ efek rata-rata keseluruhan;

$\mu_{i}=$ efek rata-rata baris ke-i level ke-j;

$\tau_{i}=$ efek faktor A level ke-i;

$\beta_{j}=$ efek faktor B level ke-j;

$\tau \beta_{i j}=$ efek interaksi faktor A dan B;

$\varepsilon_{i j k}=$ error.

3. Model regresi

$$
Y=\beta_{0}+\beta_{1} X_{1}+\beta_{2} X_{2}+\beta_{12} X_{1} X_{2}+\varepsilon
$$

dimana:

$\beta_{0}=$ parameter keseluruhan;

$\beta_{1}=$ parameter faktor $A$;

$\beta_{2}=$ parameter faktor $B$;

$X_{1}=$ variabel faktor $\mathrm{A}$;

$X_{2}=$ variabel faktor B;

$\beta_{12}=$ parameter interaksi $A$ dan $B$;

$\varepsilon=$ error

Dalam pengujian desain faktorial dua faktor, terdapat beberapa rumus yang digunakan untuk menghitung efek tiap faktor dan interaksinya. Rumus-rumus tersebut dapat dilihat pada Tabel 1. Dimana a merupakan jumlah level faktor A dan b merupakan jumlah level faktor B dan $\mathrm{n}$ merupakan banyaknya replikasi yang dilakukan.

Tabel 1: Rumus perhitungan desain faktorial 2 faktor

\begin{tabular}{|lcclc|}
\hline $\begin{array}{l}\text { Source of } \\
\text { Variation }\end{array}$ & $\begin{array}{c}\text { Sum of } \\
\text { Squares }\end{array}$ & $\begin{array}{c}\text { Degrees of } \\
\text { Freedom }\end{array}$ & \multicolumn{1}{c}{ Mean Square } & $F_{0}$ \\
\hline$A$ treatments & $S S_{A}$ & $a-1$ & $M S_{A}=\frac{S S_{A}}{a-1}$ & $F_{0}=\frac{M S_{A}}{M S_{E}}$ \\
$B$ treatments & $S S_{B}$ & $b-1$ & $M S_{B}=\frac{S S_{B}}{b-1}$ & $F_{0}=\frac{M S_{B}}{M S_{E}}$ \\
Interaction & $S S_{A B}$ & $(a-1)(b-1)$ & $M S_{A B}=\frac{S S_{A B}}{(a-1)(b-1)}$ & $F_{0}=\frac{M S_{A B}}{M S_{E}}$ \\
Error & $S S_{E}$ & $a b(n-1)$ & $M S_{E}=\frac{S S_{E}}{a b(n-1)}$ & \\
Total & $S S_{T}$ & $a b n-1$ & & \\
\hline
\end{tabular}

dengan:

$$
S S_{T}=\sum_{i=1}^{a} \sum_{j=1}^{b} \sum_{k=1}^{n} y_{i j k}-\frac{y^{2} \ldots}{a b n}
$$

$$
\begin{gathered}
S S_{A}=\frac{1}{b n} \sum_{i=1}^{a} y_{i}^{2}-\frac{y^{2} \ldots}{a b n} \\
S S_{B}=\frac{1}{a n} \sum_{j=1}^{b} y_{j}^{2}-\frac{y^{2} \ldots}{a b n} \\
S S_{\text {Subtotals }}=\frac{1}{n} \sum_{i=1}^{a} \sum_{j=1}^{b} y_{i j}^{2}-\frac{y^{2} \ldots}{a b n} \\
S S_{A B}=S S_{S u b t o t a l s}-S S_{A}-S S_{B} \\
S S_{E}=S S_{T}-S S_{\text {Subtotals }}
\end{gathered}
$$

\section{Metode Penelitian}

\subsection{Pengumpulan Data}

Tahap pengumpulan data ini dilakukan dengan membuat sampel uji sebanyak 15 buah dengan berbagai kombinasi bahan campuran dan jumlah katalis yang digunakan. Terdapat tiga level bahan campuran yang digunakan yaitu: kalsium, $\mathrm{Al}(\mathrm{OH})_{3}(\mathrm{HWF} 50)$, dan $\mathrm{Al}(\mathrm{OH})_{3}$ (HWF100). Jumlah katalis yang dicampurkan terdiri dari lima level, yaitu: $2 \mathrm{ml}, 3 \mathrm{ml}, 4 \mathrm{ml}$, $5 \mathrm{ml}$, dan $6 \mathrm{ml}$.

Sampel yang telah dibuat kemudian diukur ketangguhan materialnya dengan menggunakan metode pengujian charpy. Peralatan Charpy Test menggunakan prinsip kekekalan energi dimana untuk mengetahui besarnya energi yang dibutuhkan untuk mematahkan sampel yang diuji. Sampel uji yang digunakan untuk pengujian ini berukuran $55 \mathrm{~mm}$ x 10 $\mathrm{mm} \times 10 \mathrm{~mm}$. Sebelum diolah lebih lanjut, data yang telah diperoleh kemudian dilakukan pengujian kenormalan dan kesamaan variansi data terlebih dahulu.

\subsection{Pengolahan Data}

Berikut ini merupakan langkah-langkah pengolahan data yang dilakukan, yaitu:

1. Membuat hipotesis untuk pengujian setiap faktor

2. Melakukan analisis terhadap efek utama dan efek interaksi dari faktor yang diteliti

3. Melakukan analisis kesesuaian regresi terhadap data dengan analisa residual

4. Menentukan nilai optimal untuk tiap faktor yang diuji untuk menghasilkan nilai ketangguhan material yang terbaik 


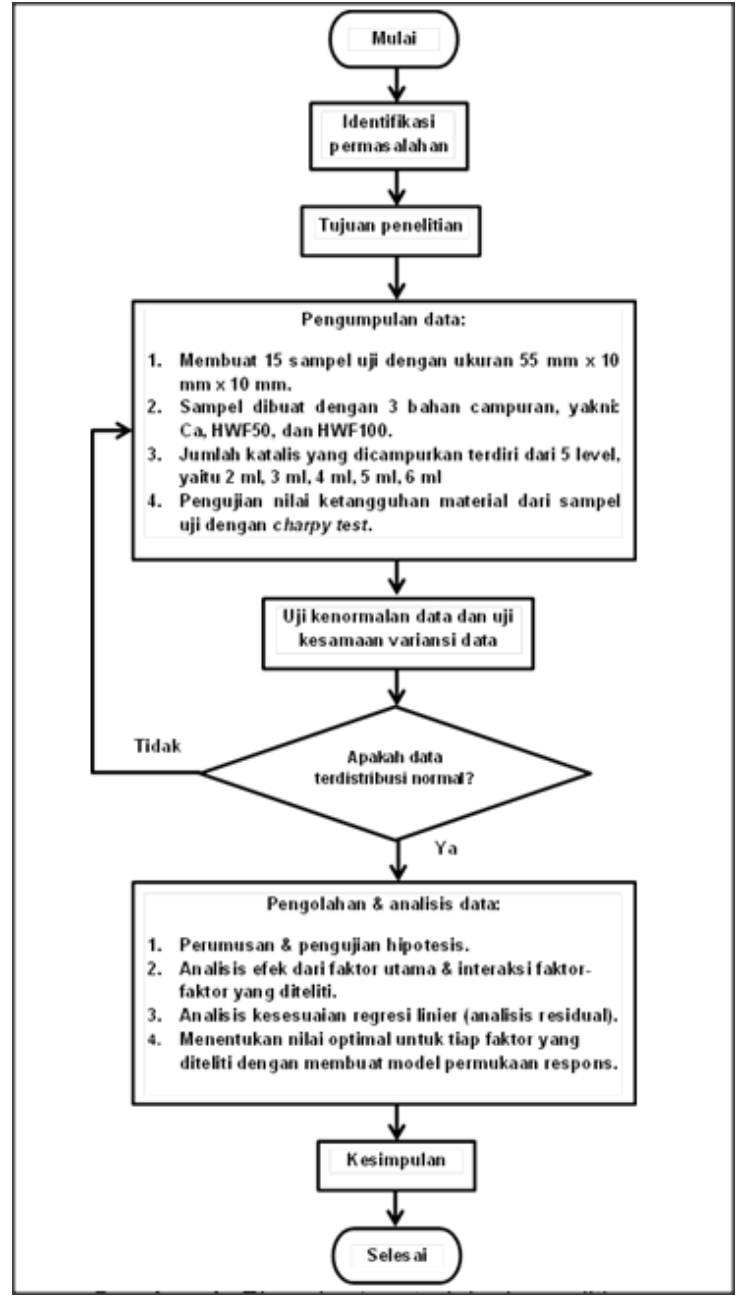

Gambar 1: Flowchart metodologi penelitian

\section{Hasil dan Pembahasan}

Hasil dari pengujian ketangguhan material dapat dilihat pada Tabel 2. Hasil pengujian kenormalan data dapat dilihat pada Gambar 3 dan uji kesamaan variansi data dapat dilihat pada Gambar 4 .

Tabel 2: Hasil pengujian ketangguhan material $\left(\mathrm{J} / \mathrm{m}^{2}\right)$

\begin{tabular}{|c|ccc|ccc|ccc|}
\hline \multirow{2}{*}{ Katalis(ml) } & \multicolumn{10}{|c|}{ Bahan campuran } \\
\cline { 2 - 10 } & \multicolumn{4}{|c}{ Ca } & \multicolumn{3}{c|}{ HWF50 } & \multicolumn{3}{c|}{ HWF100 } \\
\hline 2 & 65,99 & 57,02 & 62,71 & 55,14 & 51,83 & 58,10 & 50,77 & 47,94 & 52,03 \\
3 & 55,88 & 59,55 & 57,25 & 59,67 & 62,30 & 64,05 & 53,84 & 56,94 & 57,66 \\
4 & 52,80 & 54,19 & 51,51 & 67,04 & 74,41 & 68,23 & 48,11 & 49,03 & 46,56 \\
5 & 44,89 & 42,56 & 40,65 & 63,30 & 58,71 & 60,52 & 44,61 & 47,42 & 42,63 \\
6 & 33,44 & 29,45 & 28,40 & 51,61 & 52,65 & 47,42 & 39,31 & 40,18 & 38,99 \\
\hline
\end{tabular}

Berdasarkan hasil uji kenormalan data, dapat dilihat bahwa $p$-value yang didapatkan sebesar 0,901 dan lebih besar dari taraf signifikansi yang digunakan $(\alpha=0,05)$ sehingga dapat disimpulkan bahwa data terdistribusi normal. Pengujian untuk kesamaan variansi data juga

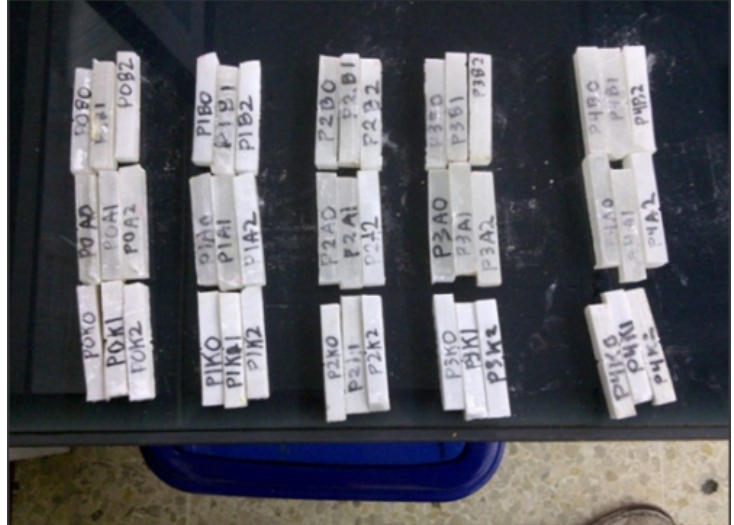

Gambar 2: Sampel uji charpy

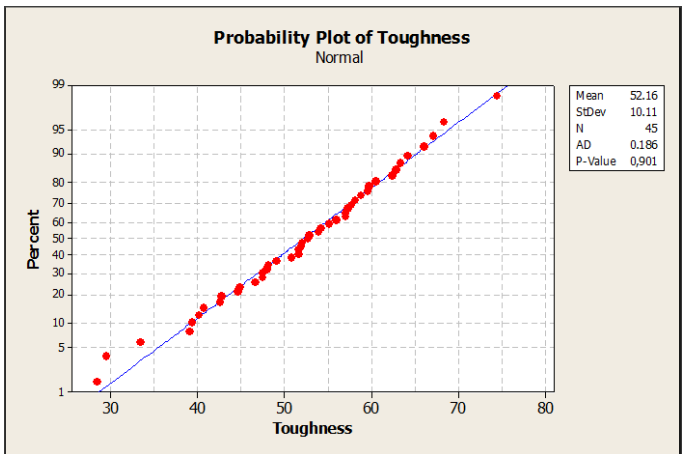

Gambar 3: Grafik uji kenormalan data

menunjukkan bahwa p-value yang diperoleh lebih besar dari taraf signifikansi yang digunakan $(\alpha=0,05)$ sehingga dapat disimpulkan bahwa standar deviasi dari setiap kumpulan data tersebut sama.

Data kemudian diuji dengan metode desain faktorial untuk menentukan besarnya pengaruh dari setiap faktor yang diteliti terhadap hasil percobaan (ketangguhan). Perumusan hipotesis untuk tiap faktor yang akan dianalisa adalah sebagai berikut:

$H_{01}=$ Faktor katalis tidak berpengaruh secara signifikan terhadap ketangguhan material;

$H_{11}=$ Faktor katalis memiliki pengaruh yang signifikan terhadap ketangguhan material;

$H_{02}=$ Faktor bahan campuran tidak berpengaruh secara signifikan terhadap ketangguhan material;

$H_{12}=$ Faktor bahan campuran memiliki pengaruh yang signifikan terhadap ketangguhan material;

$H_{03}=$ Interaksi faktor katalis dan bahan campuran tidak berpengaruh secara signifikan terhadap ketangguhan material;

$H_{13}=$ Interaksi faktor katalis dan bahan campuran memiliki pengaruh yang signifikan terhadap ketangguhan material. 


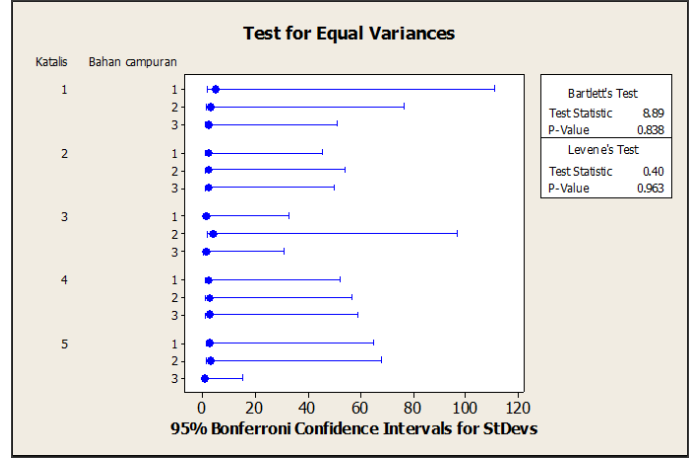

Gambar 4: Hasil uji kesamaan variansi

Setelah membuat hipotesis, data yang diperoleh kemudian diuji untuk menentukan kebenaran dari masing-masing hipotesis yang dibuat.

Tabel 3: Hasil uji ANOVA

\begin{tabular}{|c|c|c|c|c|c|c|}
\hline Source & DF & Seq SS & Adj SS & Adj MS & F & P \\
Katalis & 4 & 2045,03 & 2045,03 & 511,26 & 79,05 & 0,000 \\
Bahan campuran & 2 & 1280,45 & 1280,45 & 640,22 & 98,99 & 0,000 \\
Katalis*bahan campuran & 8 & 979,31 & 979,31 & 122,41 & 18,93 & 0,000 \\
Error & 30 & 194,03 & 194,03 & 6,47 & & \\
Total & 44 & 4498,82 & & & & \\
\hline S = 2,54319 & & \multicolumn{7}{|c|}{ R-Sq (adj) $=93,67 \%$} \\
\hline
\end{tabular}

Dari hasil uji ANOVA pada tabel 3, dapat dilihat bahwa $p$-value yang diperoleh sangat kecil untuk setiap faktor yang diteliti sehingga dapat diperoleh kesimpulan untuk menolak $H_{01}, H_{02}$, dan $H_{03}$.

Untuk dapat melihat signifikansi efek dari setiap faktor yang diteliti maka dibuat grafik yang menunjukkan rata-rata efek dari setiap faktor utama dan faktor interaksi. Grafik pada Gambar 5 menunjukkan efek faktor utama, dan efek interaksi diilustrasikan pada Gambar 6.

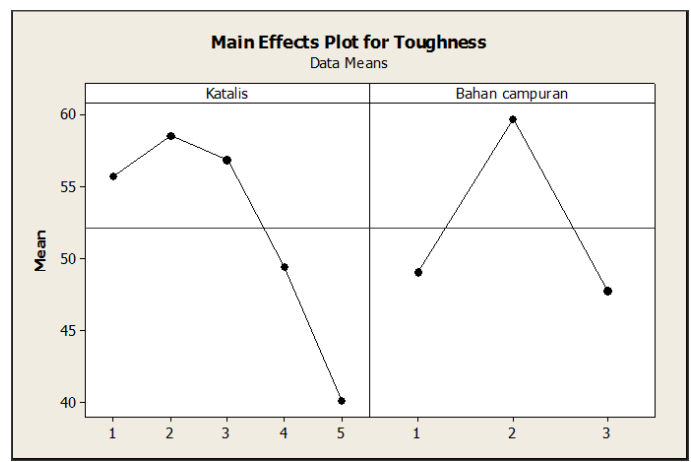

Gambar 5: Grafik efek faktor utama

Pada Gambar 5 dapat dilihat bahwa efek dari faktor katalis mempunyai kecenderungan naik pada level 2 dan selanjutnya turun untuk penambahan jumlah katalis hinggal paling rendah

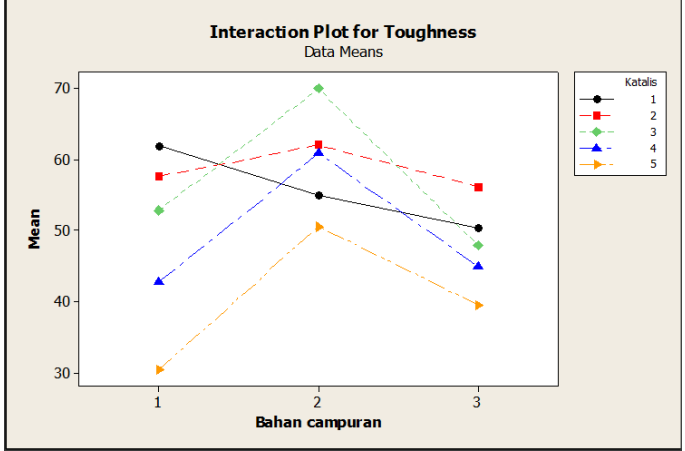

Gambar 6: Grafik efek faktor interaksi

pada level 5. Faktor bahan campuran mempunyai kecenderungan untuk meningkatkan ketangguhan material pada level 2.

Pada Gambar 6 dapat dilihat bahwa pengaruh faktor interaksi dari faktor katalis dan bahan campuran terhadap ketangguhan material mempunyai kecenderungan yang sama yaitu kenaikan pada faktor bahan campuran level 2 . Kelainan terlihat pada faktor bahan katalis level 1 dimana nilai ketangguhan justru turun pada faktor bahan campuran level 2. Pada grafik dapat dilihat bahwa nilai maksimum ketangguhan material dicapai pada penggunaan bahan campuran level 2 dan katalis level 3, walaupun demikian nilai ketangguhan untuk penggunaan katalis pada level 3 dengan berbagai macam jenis bahan campuran berfluktuasi sangat tinggi.

Untuk mengukur apakah hasil regresi linier yang dibuat sesuai dengan data yang analisa, maka dilakukanlah analisa residual terhadap data tersebut. Pada Gambar 7 ditampilkan diagram pencar hubungan residual terhadap faktor katalis, pada Gambar 8 untuk hubungan residual terhadap faktor bahan campuran, pada Gambar 9 untuk hubungan residual terhadap ketangguhan material dan pada Gambar 10 untuk hubungan residual terhadap probabilitas kenormalan data.

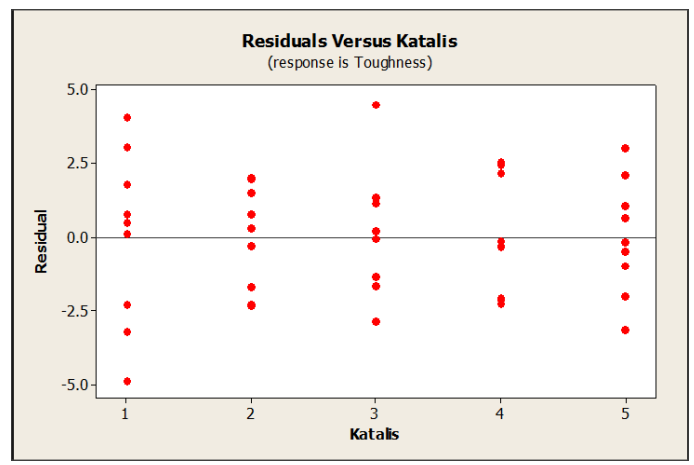

Gambar 7: Diagram pencar residual-katalis 


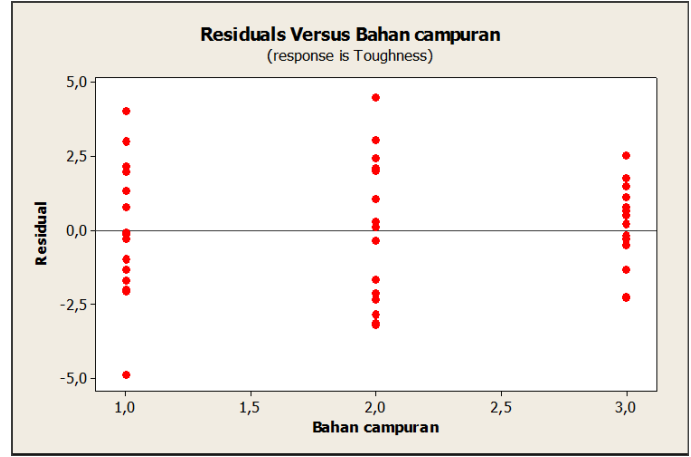

Gambar 8: Diagram pencar residual-bahan campuran

Pada Gambar 7 dan 8 terlihat bahwa terdapat perbedaan variansi residual yang cukup terlihat. Untuk faktor katalis terdapat variansi residual yang cukup tinggi pada level 1 dan 3 sedangkan untuk faktor bahan campuran terdapat variansi yang cukup tinggi pada level 1 dan 2. Pada Gambar 9 terlihat variansi residual cenderung naik seiring dengan kenaikan nilai ketangguhan material. Pada Gambar 10 terlihat bahwa variansi residual tidak ada yang berada terlalu jauh dari garis regresi sehingga persebaran variansi residualnya dapat dikatakan terdistribusi normal. Walaupun demikian, penyimpangan nilai residual tersebut tidaklah terlalu besar sehingga tidak terlalu mempengaruhi hasil analisa dan kesimpulan.

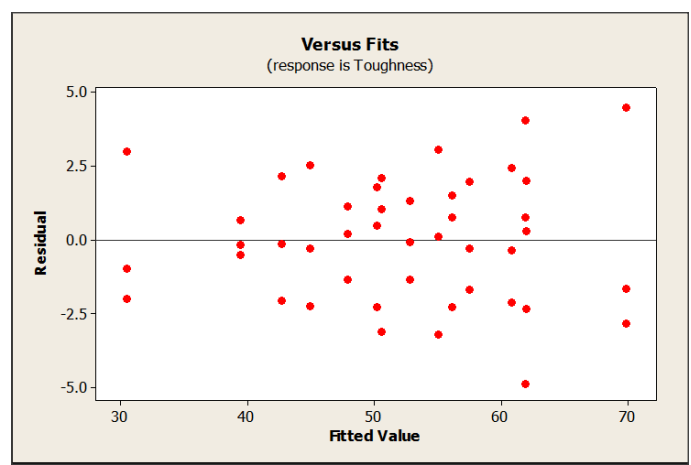

Gambar 9: Diagram pencar residualketangguhan material

Untuk mengetahui nilai optimal dari kedua faktor yang diteliti (katalis dan bahan campuran) maka dibuatlah model permukaan respons (response surface) dari data yang diperoleh seperti yang ditunjukkan pada Gambar 11. Selain itu, dibuat pula plot optimasi (Gambar 12) agar terlihat lebih jelas nilai dari faktor yang diteliti dalam mendapatkan nilai ketangguhan material yang tinggi. Persamaan yang digunakan untuk membuat model permukaan res-

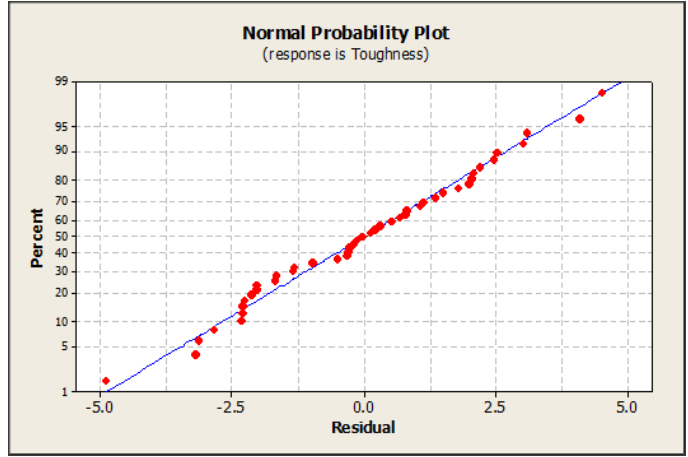

Gambar 10: Diagram pencar residualkenormalan data

pons tersebut dapat dilihat pada Tabel 4.

Tabel 4: Analisa regresi permukaan respons

\begin{tabular}{|c|c|c|c|c|}
\hline Term & Coef & SE Coef & T & P \\
\hline Konstanta & 26,565 & 7,2835 & 3,647 & 0,001 \\
\hline Katalis & 4,341 & 2,8611 & 1,517 & 0,137 \\
\hline Bahan campuran & 37,587 & 6,3374 & 5,931 & 0,000 \\
\hline Katalis*katalis & $-2,145$ & 0,4228 & $-5,073$ & 0,000 \\
\hline Bahan campuran*bahan campuran & $-11,255$ & 1,5007 & $-7,500$ & 0,000 \\
\hline Katalis*bahan campuran & 2,252 & 0,6127 & 3,676 & 0,001 \\
\hline
\end{tabular}

Berdasarkan hasil pada tabel 4, maka dapat dibuat persamaan sebagai berikut: Ketangguhan $=26,565+4,341 \mathrm{a}+37,587 \mathrm{~b} \quad 2,145 \mathrm{a}^{2}$ $11,255 b^{2}+2,252 a b$ dimana:

$\mathrm{a}=$ Jumlah katalis, $2 \leq \mathrm{a} \leq 6$, a $\varepsilon$ B

$\mathrm{b}=$ Jenis bahan campuran, $1 \leq \mathrm{b} \leq 3, \mathrm{~b} \varepsilon \mathrm{B}$

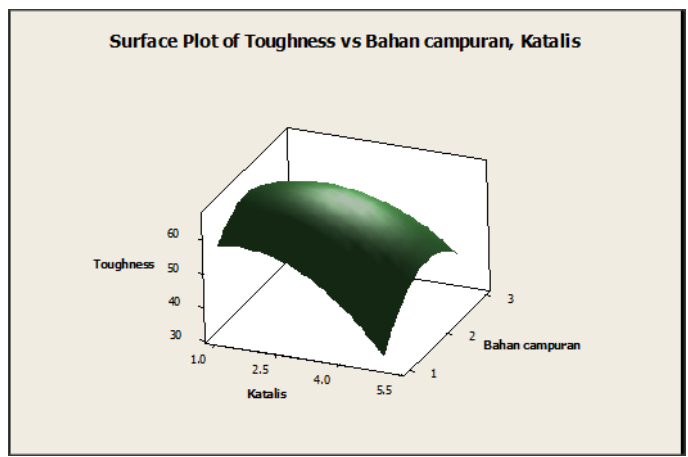

Gambar 11: Model permukaan respons

Pada Gambar 11 dapat dilihat bahwa untuk mendapatkan ketangguhan material yang optimal maka nilai dari faktor katalis dan bahan campuran yang harus digunakan mendekati angka 2 (2,0101 untuk faktor katalis dan 1,8687 untuk faktor bahan campuran) sehingga dapat disimpulkan bahwa untuk mendapatkan nilai ketangguhan material yang optimum sebaiknya digunakan katalis level 2 dan bahan campuran level 2 yaitu katalis dengan jumlah $3 \mathrm{ml}$ dan bahan campuran $\mathrm{Al}(\mathrm{OH})_{3}$ dengan spesifikasi HWF50. 


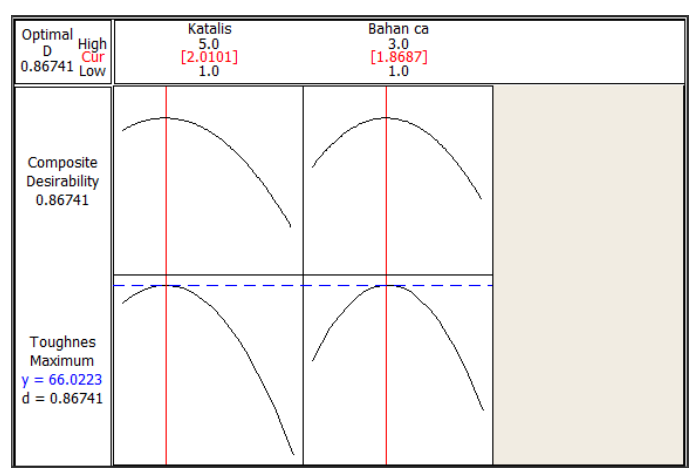

Gambar 12: Plot optimasi faktor

\section{Kesimpulan}

Berdasarkan hasil pengolahan data dan analisis yang telah dilakukan, dapat disimpulkan beberapa hal, yaitu:

1. Untuk meningkatkan ketangguhan material, maka nilai paling optimal diperoleh pada penggunaan jenis bahan campuran $\mathrm{Al}(\mathrm{OH})_{3}$ spesifikasi HWF50 dengan jumlah bahan katalis $3 \mathrm{ml}$.

2. Pada jumlah $2 \mathrm{ml} 3 \mathrm{ml}$, faktor katalis meningkatkan ketangguhan material, namun menyebabkan penurunan ketangguhan material pada jumlah di atas $3 \mathrm{ml}$

3. Nilai ketangguhan material paling tinggi dicapai dengan menggunakan bahan campuran $\mathrm{Al}(\mathrm{OH})_{3}$ dengan spesifikasi HWF 50 .

4. Nilai ketangguhan material cenderung tinggi untuk bahan campuran $\mathrm{Al}(\mathrm{OH})_{3}$ spesifikasi HWF 50 dan mempunyai nilai yang lebih rendah untuk bahan campuran kalsium dan $\mathrm{Al}(\mathrm{OH})_{3}$ spesifikasi HWF 100. Hal ini cenderung sama untuk semua jumlah katalis yang ditambahkan dengan pengecualian jumlah katalis sebanyak $2 \mathrm{ml}$ yang mempunyai nilai ketangguhan tertinggi bila dicampurkan dengan kalsium.

\section{Ucapan Terima Kasih}

Penelitian ini mendapatkan dana hibah dari Lembaga Penelitian dan Publikasi Ilmiah (LPPI) Universitas Tarumanagara, Jakarta. Oleh karena itu, pada kesempatan ini penulis menyampaikan rasa terima kasih kepada LPPI Untar dan juga semua pihak yang terlibat sehingga penelitian ini dapat diselesaikan.

\section{Daftar Pustaka}

Ariani, Dorothea Wahyu. (1993). Manajemen Kualitas. Jakarta: Ghalia Indonesia.

Bagchi, Tapan P.. (1993). Taguchi Methods Explained: Practical Steps to Robust Desain. India: Prentice Hall.

Belavendram, Nicolo. (1995). Quality By Design. India: Prentice Hall.

Decker, Marcel. (1986). Goodness-of-fit Techniques. Marcel Decker.

Ishikawa, Kaoru. (1989). Teknik Penuntun Pengandalian Mutu. Jakarta: Mediyatama Sarana Perkasa.

Intertek Plastics Technology Laboratories. Izod Impact Testing (Notched Izod). [Online]. Diakses dari: http://www.ptli.com/testlopedia/tests/izodd256-iso180.asp [2013, 26 Mei].

Mathwave Technologies, Goodness of Fit Test, [Online], Diakses dari: http:/ / www.mathwave.com/articles/good ness_of_fit.html [2013, 30 Mei].

Montgomery, Douglas C. (2005). Design and Analysis of Experiments (6th ed.). Arizona: John Wiley \& Sons,Inc..

Soejanto, Irwan. (2009). Desain Eksperimen dengan Metode Taguchi. Jakarta: Graha Ilmu.

Soendari, Tjutju, Metode Penelitian Eksperimen, [Online], Diakses dari: http://file.upi.edu/Direktori/FIP/JUR._PEND. _LUAR_BIASA/195602141980032-TJUTJU SOENDARI/Power_Point_Perkuliahan/Eks perimen/PENELITIAN_EKSPERIMEN.ppt \%5BCompatibility_Mode\%5D.pdf [2013， 30 Mei] 